\title{
Organização Empresarial em Alfred Marshall
}

Jaques Kerstenetzky

Professor Adjunto do Instituto de Economia da UFRJ

\section{RESUMO}

Encontra-se na obra de Marshall uma abordagem ao ambiente empresarial que difere de sua tradicionalmente considerada contribuição à economia. Embora Marshall seja o fundador da vertente do equilíbrio parcial da microeconomia, seu trabalho no tema da organização empresarial é muito mais rico do que esta contribuição específica. $O$ artigo explora a análise de cunho histórico e institucional desenvolvida por Marshall no tema da firma, dos mercados e dos ambientes empresariais. Como resultado, sugere que Marshall pode ser apontado como precursor de abordagens contemporâneas ao tema, como a abordagem das capacitações organizacionais, e da grande corporação americana, de autores como Berle e Means e Chandler.

\section{PALAVRAS-CHAVE}

firma, mercado, organização empresarial, Marshall

ABSTRACT

We can find in Marshall's works an approach to business environments that is different from his traditionally accepted contribution to mainstream economics. Though Marshall is indeed the founder of the partial equilibrium analysis branch of traditional microeconomics, his work on the theme of business is much richer than his specific contribution to microeconomics.

The article explores Marshall's institutional and historical analysis of firms, markets and of business environments. As an outcome, it suggests that Marshall can be pointed out as a forerunner of modern approaches to the theme, like Berle and Means's and Chandler's works on corporations, and the capabilities approach to the theory of the firm.

KEY WORDS

firm, market, business organization, Marshall

JEL Classification

B3I, LOO 
Este artigo trata da visão mais ampla de Alfred Marshall a respeito da natureza de firmas e mercados. Sua motivação está em podermos encontrar na obra de Marshall uma abordagem a este tema que difere da que é tradicionalmente considerada como sendo sua efetiva contribuição à Economia. Isto se explica pelo fato de que, ainda que Marshall seja o fundador da vertente do equilíbrio parcial da tradicional microeconomia, sua obra é mais rica do que sua contribuição a esta disciplina. Observe-se que o próprio autor afirmou que a abordagem estática desenvolvida nos seus Princípios de Economia é apenas uma primeira aproximação aos problemas econômicos. ${ }^{1}$ Uma evidência desse caráter de primeira aproximação é sua complementação nos Princípios com farto material que não se enquadra facilmente na abordagem estática, característica do estilo marshalliano de combinar material institucional com o que hoje se considera análise econômica. No caso de Industry and Trade, menos lido do que os Principles, trata-se definitivamente de uma obra de organização industrial caracterizada por tratamento histórico e institucional de firmas, mercados e economias nacionais.

Observe-se também que, em uma leitura desavisada dos Principles, o material histórico e institucional pode não ser valorizado porque o estilo de exposição do autor, mais próximo à riqueza smithiana do que à lógica ricardiana, contrasta com as tendências de exposição lógica e formal que se afirmaram crescentemente ao longo do século XX. A exposição marshalliana alterna construções de teoria pura e níveis menos abstratos de teorização.

A exposição dos elementos da abordagem marshalliana de firmas e mercados deste artigo tem como ponto de partida a crítica da microeconomia tradicional, de forma a tornar explícitas as diferenças entre os dois enfoques. No entanto, como isto será empregado como um artifício de exposição, o que estará sendo comparado à abordagem marshalliana é uma caricatura ultrapassada do mainstream. Um critério para o uso desta caricatura baseia-se

1 Principles, livro V, Capítulo XII, $\$$ 3. O "primeiro volume" dos Principles foi escrito tendo como peça central os modelos estáticos de determinação de preços que Marshall começara a desenvolver anteriormente. Sua intenção era oferecer uma abordagem dinâmica ao funcionamento das economias capitalistas, a ser apresentada em um segundo volume dos Principles. Este nunca chegou a ser concluído e, em seu lugar, foram publicados dois livros nos últimos anos antes de sua morte - Industry and Trade e Money, Credit and Commerce - aproveitando escritos reunidos ao longo de sua vida, dentre eles material preparatório do "segundo volume dinâmico". 
no fato de que ela está bastante próxima daquilo em que se converteu a própria vertente da microeconomia do equilíbrio parcial alguns anos após a morte de Marshall, induzindo várias gerações de economistas a pensar que a caricatura correspondia à contribuição marshalliana. Esta observação se faz necessária como reconhecimento de que a Economia (incluindo correntes ortodoxas e heterodoxas) tem, nas últimas décadas, envidado esforços que têm diversificado as respostas aos problemas do campo em discussão. A abordagem marshalliana é assim uma alternativa entre outras, podendo inclusive integrar-se com algumas delas. ${ }^{2}$

Assim, a seção a seguir corresponde à descrição resumida da microeconomia tradicional. A estruturação do artigo fica clara ao final da seção: o seu último parágrafo aponta os temas que marcam as diferenças entre a abordagem de Marshall e a caricatura da microeconomia. O restante do artigo se estrutura com uma seção dedicada a cada um destes temas.

\section{MICROECONOMIA TRADICIONAL COMO HOMEM DE PALHA}

Não seria controverso afirmar que mercado é o conceito central da ciência econômica. No mundo real, o mercado soluciona o problema teórico de coordenação de um sistema econômico em que as decisões são descentralizadas entre um número elevado de agentes autônomos e auto-interessados. A demonstração desta capacidade coordenadora e de produção da ordem econômica do mercado é o que os economistas procuram demonstrar desde Adam Smith, por meio da construção de modelos que são sua representação.

No entanto, apesar de cada vez mais sofisticados do ponto de vista formal, modelos de mercado são, com freqüência, inadequadamente concebidos como representação de como os mercados efetivamente realizam a tarefa da coordenação das decisões. As próprias definições de mercado, quando fornecidas, tendem à supersimplificação, como no exemplo representativo de Samuelson e Nordhaus (1992, p. 36, grifo adicionado): "A mechanism by which buyers and sellers of a commodity interact to determine its price and quanti-

2 Isto vale, por exemplo, para a nova economia institucional. Ver, a respeito, KERSTENETZKY (2000). 
ty." Como mecanismo, aspectos institucionais estão ausentes da representação ou, ao menos, os mercados são vistos como institucionalmente homogêneos. Em consonância, os esforços teóricos consistem na construção de modelos que concebem curvas de oferta e demanda e sua simples agregação e encontro.

Devemos considerar que essas representações se concebem para resolver o problema de alocação de recursos escassos a usos alternativos, tido pelo mainstream como o problema econômico. Porém, o problema alocativo estaticamente discutido não proporciona a estrutura ideal para consideração dos importantes elementos relacionados à tecnologia e conhecimento, particularmente sob mudança e evolução. Insuficiências do método estático se afiguram sob a forma de ausência de discussão da forma pela qual os mercados se constituem, de como eles são diversamente organizados, e de como a informação flui no seu interior.

No que se refere às firmas, estas são retratadas pela microeconomia na forma de uma pálida caricatura de unidade de negócios, somente apropriada como unidade de um sistema de alocação de recursos, no qual a firma é meramente o local onde capital, trabalho e recursos naturais se combinam segundo as tecnologias existentes para produzir os bens que satisfazem as necessidades de consumidores soberanos. A tecnologia é tratada como bem livre, e habilidades, capacitações, organização interna, hierarquia e estratégias não são discutidas - e muito menos mudanças nestes elementos.

A microeconomia tradicional tem sempre por referência a concorrência perfeita. Este é o modelo que representa o ambiente econômico ótimo. Suas condições podem ser resumidas como um sistema econômico ou mercado no qual há um número infinito de compradores e vendedores, de forma que cada comprador ou vendedor tem sempre alternativas em termos de com quem transacionar; não há barreiras à mobilidade de fatores, suposição que garante que oportunidades vantajosas não serão monopolizadas; há perfeito conhecimento, de forma que todos possuem as informações necessárias para escolher entre alternativas de transações; e os produtos são homogêneos, de maneira que os compradores não encaram os produtos de competidores diferentemente e, assim, os produtores não derivam poder de mercado de diferenciação de produtos. 
Quanto aos modelos de concorrência imperfeita, é importante perceber que sua referência é ainda a concorrência perfeita - eles são meramente sua negação, posto que imperfeição é a ausência de alguma das condições do ideal, com análise de conseqüências sobre a determinação de preços. Assim, o problema com a construção teórica representada pela concorrência perfeita (incluída a sua negação, a concorrência imperfeita) está em que ela freqüentemente substitui a efetiva compreensão das condições da vida econômica. Em relação a este ponto, Ronald Coase afirmou certa vez que os economistas costumam rotular de imperfeições as situações que sentem dificuldade em compreender. (COASE, 1988). Poderíamos aprofundar ainda mais esta linha de argumentação, e apontar que elementos rotulados por economistas como imperfeições são parte integrante do ambiente institucional-empresarial, sendo importantes para o funcionamento do sistema econômico. $^{3}$

É possível concluir esta representação da microeconomia tradicional com a constatação de que está nela ausente a análise dos arranjos que permitem o relacionamento de agentes e seu conteúdo institucional. O contraste entre a microeconomia tradicional e a obra de Marshall quanto a este ponto se verifica pelo tratamento dispensado por este autor ao conhecimento e à organização como elementos de coordenação e capacitação; à natureza da firma, discutida em torno das capacitações organizacionais; aos esforços de vendas por parte das empresas; aos agentes do mercado e suas funçôes; e, finalmente, à discussão de ambientes empresariais correspondentes a diferentes épocas e nações. As seções seguintes abordam estes temas em seqüência; o primeiro

3 Este ponto foi desenvolvido de maneira feliz por RICHARDSON (1990), economista neomarshalliano que critica o modelo de concorrência perfeita explorando dois elementos presentes na obra de Marshall: a incerteza que faz de todo agente um especulador, e a natureza dos lucros industriais, vistos como quase-rendas ao invés de lucros normais. Segundo Richardson, a concorrência perfeita encerra uma falha lógica relacionada às condiçôes informacionais que suportam a decisão de investimento das empresas, já que uma oportunidade lucrativa aberta a todos não é oportunidade lucrativa. As condições de informação capazes de induzir a massivos investimentos em condições de incerteza são, para Richardson, o que outros economistas chamam de imperfeiçôes. Barreiras à entrada, parcelas de mercado e capacidades náo difundidas são as condiçóes que dão às firmas confiança suficiente na obtenção de lucros de forma a levá-las a investir. Assim, é a imperfeição que assegura o investimento e o bom funcionamento das economias capitalistas, particularmente após as economias de escala que emergiram com a segunda revolução industrial. Assim, o traço característico dos mercados a que os economistas chamam de imperfeitos não é a restrição das quantidades para benefício por meio de preços elevados, mas a confiança nas "imperfeições" que asseguram minimamente que a ampliação de capacidade será posta a produzir, viabilizando os investimentos. 
destes temas, em particular, tratado na próxima seção, por introduzir os elementos e a perspectiva essenciais do artigo, apresenta e integra os temas tratados nas seguintes.

\section{MARSHALL E A IMPORTÂNCIA DO CONHECIMENTO E DA OR- GANIZAÇÃO}

Marshall não via a produção simplesmente como combinação de capital, trabalho e recursos naturais. Firmas, mercados e economias contam com organização e conhecimento em adição à trinca tradicional de fatores de produção. Conhecimento e organização são, desta forma, dotação e objeto de desenvolvimento tanto no âmbito público como no privado. (Principles, Livro IV, Capítulo $1, \$ 1)$.

Na perspectiva marshalliana, organização aparece no âmbito privado das firmas sob a forma da hierarquia, da supervisão e controle das operações, da divisão do trabalho no interior da empresa, das formas jurídicas que estabelecem de quem são a propriedade e o controle. Há ainda, sob o rótulo de conhecimento, a experiência, as soluções desenvolvidas e as capacitações acumuladas e reunidas individualmente pelas firmas. Nos setores e mercados há os segredos e práticas, os relacionamentos e instituições compartilhadas no interior de setores de atividade e distritos industrais especializados, e aqueles que resultam da interação de diferentes setores de atividade; aparecem sob a forma de relacionamento de fornecedores e compradores de insumos, produtores e consumidores, de canais de comercialização estabelecidos, quer por firmas comerciais independentes, quer pelos produtores ou ainda vendedores de uma mesma mercadoria que se articulam para coordenar seus interesses $^{4}$; ou seja, por meio de padrões institucionalizados de relacionamento entre agentes, que incluem tanto competição como cooperação. Ainda no âmbito público, a atividade econômica é condicionada por aspectos históricos e institucionais mais amplos, parcela dos quais ligados à esfera de ação do Estado, como o sistema educacional, a política de defesa da concorrência, o sistema legal, eventuais políticas de incentivo à indústria etc.

4 Por exemplo, sob a forma de um cartel, ou ainda de um trust. 
A importância atribuída por Marshall à organização e ao conhecimento explica a sua maneira de compreender a competição e o funcionamento dos mercados como variedade e complexidade. A leitura dos Principles deixa claro que o modelo de equilíbrio parcial é apenas a discussão de como se formam os preços, a peça estática da obra marshalliana. Se preços em um mercado podem ser convergentes na competição, porque ninguém aceita um preço se há outros como alternativas mais favoráveis, ${ }^{5}$ outros elementos econômicos não apresentam difusão e convergência fácil, seja no plano da firma, seja no de setores ou nações.

\section{A PRODUÇÃO E A FIRMA MARSHALLIANA}

Esta seção desenvolve um tema do qual a tradicional microeconomia se abstraiu: a organização interna das firmas e sua acumulação de recursos e capacitações. Corresponde ao nível privado da proposição de Marshall sobre conhecimento e organização.

Uma das maneiras pelas quais a firma está presente na análise marshalliana e que não será aqui tratada - é a firma representativa. Ciente de que os mercados são povoados por firmas heterogêneas em idade e capacitações, Marshall criou a firma representativa - uma firma na plenitude de seu ciclo de vida, vigor competitivo, capacidades e acesso a economias internas - como peça teórica da análise estática do equilíbrio parcial dos mercados, apresentada na conclusão do livro IV e desenvolvida no livro V dos Principles. Foi somente mais tarde que uma seqüência de contribuições de outros autores acabou por substituir a solução da firma representativa por firmas homogêneas povoando os mercados no equilíbrio de longo prazo. (MOSS, 1984).

Marshall desenvolve uma outra abordagem da firma - a que aqui se quer enfatizar - quando discute os agentes da produção nos capítulos XI e XII do livro IV dos Principles. ${ }^{6}$ Nela o tema é a natureza da firma, reconhecida como

5 Principles, livro V, capítulo III, $\$ 4$.

6 Para ser exato, a discussão do livro IV é mais sobre o empresário do que propriamente sobre a firma. Para efeito deste artigo, não há qualquer problema em entender a discussão de empresário e de firma como pertencendo ao mesmo tema. 
agente capitalista. Nesta qualidade, a firma se expande, como a firma clássica que acumula capital. Mas em Marshall, mais do que acumular capital, a firma acumula capacitações, conhecimento, desenvolve sua organização interna (incluindo hierarquia e relações com os trabalhadores), estabelece e amplia sua clientela. É desta maneira que a discussão de firmas e empresários do livro IV dos Principles faz de Marshall o precursor da abordagem contemporânea de capacitações organizacionais. ${ }^{7} \mathrm{O}$ conhecimento e as capacidades das empresas se desenvolvem em um ambiente competitivo e inovativo, no qual a sobrevivência da firma depende de sua habilidade em introduzir novas soluções aos problemas dos negócios, e em lidar com os problemas que decorrem do crescimento. Essas soluções se referem às diversas áreas da atividade empresarial, como as áreas da produção, das finanças, das relações com os trabalhadores, fornecedores, e consumidores. Além da competência na organização e supervisão das atividades internas, deve o empresário, segundo Marshall,

"ter um conbecimento completo das coisas de seu ramo. Deve ter a capacidade de prever os amplos movimentos da produção e do consumo, de visualizar onde há oportunidade para oferecer uma nova mercadoria que atenderá a uma necessidade real ou para aperfeiçoar o plano de produção de uma antiga mercadoria. Deve ser capaz de julgar prudentemente e assumir riscos corajosamente; e, obviamente, entender dos materiais e maquinaria utilizados em seu ramo."

(Principles, Livro IV, Capítulo XII, $\$$ 5)

No trecho citado, apesar de usar a palavra risco onde Knight empregaria incerteza, é possível entender a inclusão no conhecimento, sob a forma de capacidade, da idéia knightiana de tomada de decisões baseada na antecipação de desdobramentos futuros de ações, empregando informação inevitavelmente incompleta e complementada por opiniões, tendo como base a expe-

7 Para uma apreciação da abordagem das capacitações organizacionais e contraste e possibilidade de integração com a abordagem neo-institucionalista, ver LANGLOIS \& FOSS (1999). Para uma interessante apreciação do tema por um eminente historiador, ver CHANDLER (1992). 
riência presente. ${ }^{8}$ No trecho acima, o conhecimento específico das "coisas" do setor figura como base para lidar com o que modernamente se entende por incerteza.

Não há na obra de Marshall a proposição ou crença na convergência e difusão de conhecimento de maneira a fazer com que cada mercado tenda a apresentar uma população de firmas idênticas. O autor vê o ambiente empresarial como em permanente mudança, embora sem o aspecto radical da destruição criadora de Schumpeter. ${ }^{9}$ E, da mesma forma que para este autor, há na mudança uma importante fonte endógena: as soluções empresariais mencionadas anteriormente são fator permanente de mudança, com firmas sendo criadas e sobrevivendo se conseguem abrir caminho na competição por meio de uma idéia fértil em algum dos campos dos negócios, outras já estabelecidas crescendo e lidando com os problemas de colher rendimentos crescentes e vender quantidades de produto crescentes, e outras ainda em decadência e ossificadas, continuando a usar soluções que um dia foram inovadoras.

Ainda seguindo a tradição clássica, Marshall vê os rendimentos crescentes como predominantes na atividade industrial. ${ }^{10}$ Rendimentos crescentes se manifestam tanto no plano da firma como no do conjunto de firmas, seja em mercados, regióes ou economias nacionais. É neste contexto que Marshall propõe os conceitos de economias internas e economias externas. ${ }^{11}$ As economias internas correspondem a mudanças no desempenho que acompanham o aumento da dimensão das firmas. ${ }^{12} \mathrm{O}$ desempenho das firmas é favorecido pelo seu tamanho devido a vantagens na compra de insumos em maior quantidade a preços mais vantajosos, no acesso a formas de comercialização e propaganda bloqueadas a pequenos negócios, na possibilidade de uso de maquinaria, trabalho e gerência especializados, na capacidade de

8 KNIGHT (1921, terceira parte, capítulo VII). Em apoio a esta proposição de aproximar a visão empresarial de Marshall à de Knight, podemos lançar mão de outra citação, na qual Marshall diz não haver meio do empresário se assegurar contra falhas em decisões, a não ser transferindo o risco e a função. (Industry and Trade, parte II, cap. 6, \$1).

9 SCHUMPETER (1979, capítulo VII).

10 Ver, por exemplo, Principles, livro IV, capítulo XIII.

$11 \mathrm{O}$ que se segue explora as economias internas. As economias externas são abordadas mais brevemente na seção que trata do último tema, o plano das regióes e naçóes.

12 Principles, livro IV, capítulo XI. 
bancar os custos e o risco da atividade de pesquisa. Esses aspectos são em parte explicados como vantagens da especialização e da divisão do trabalho ao nível da firma.

A proposição de economias internas dá sempre margem, em teoria econômica, à discussão do problema da incompatibilidade de rendimentos crescentes e concorrência. Marshall, porém, não pensava nestes termos. Em primeiro lugar, não era claro, para ele, o saldo negativo de monopolização com rendimentos crescentes no que se refere a preços e quantidades:

"Mas onde isto pode ser feito [assumir que a firma individual é gevenciada com habilidade e iniciativa, e que tem acesso ilimitado ao capital], podemos gevalmente concluir que a curva de oferta da mercadoria, se não monopolizada, apresentaria preços mais elevados do que aqueles da curva de oferta de monopólio; e, portanto, a quantidade da mercadoria produzida em equilibrio sob concorrência livre seria inferior à que igualaria preço de demanda e de oferta de monopólio."

$$
\text { (Principles, Livro V, Capítulo XIV, \$5) }
$$

Em segundo lugar, Marshall analisou em seu Industry and Trade as tendências da organização industrial que observava no início do século XX, que se manifestavam como prevalência das economias internas sobre as externas, pelas influências técnicas que ampliavam o tamanho das unidades produtivas típicas, pelo desenvolvimento de mercados de capitais e sociedades anônimas, e de novas formas de comercialização igualmente associadas ao agigantamento dos negócios. Não é o lamento da perda de um mundo idílico formado de pequenas empresas que encontramos no $I \& T$, mas a análise de um fenômeno histórico movido pelo desenvolvimento. Neste âmbito, as tendências a monopolização foram por Marshall entendidas como passíveis de regulamentação com o objetivo de resguardar o interesse mais amplo da sociedade. $^{13}$

13 Ver Industry and Trade, Livro III capítulo VII, onde as observações sobre as tendências de monopolização na economia americana são temperadas com aprovação porque acompanhadas de monitoramento e regulamentação por parte do poder público. 
Por fim, as vantagens do tamanho e monopolização não se encerram nas de caráter estático; parte das vantagens é cumulativa e envolve tempo e processo para sua obtenção, como as que dependem de experiência e aprendizado, ou ainda a formação e crescimento de equipes de trabalhadores integrados na hierarquia da empresa, e a formação de clientela. Assim, se a perspectiva não é unicamente a estática, um grande tamanho não é meramente uma opção dentre plantas dispostas ao longo de uma curva, mas algo que resulta de um processo de crescimento. Em sua idéia de ciclo de vida da firma (familiar) Marshall propôs que, como o crescimento envolve tempo, firmas mais antigas e maiores, gerenciadas por herdeiros não selecionados pelo mercado para substituir o seu vigoroso fundador, e utilizando envelhecidas soluções aos problemas empresariais, tenderão a decair, sendo repostas por novas firmas criadas por vigorosos empresários que portam novas soluções aos mesmos problemas. ${ }^{14}$ A monopolização não deve chegar a ocorrer.

Neste ponto da análise das tendências à monopolização chegamos a um tema específico na discussão marshalliana da firma: o da influência da forma jurídica da organização da empresa sobre o seu desempenho, ou seja, da comparação entre empresas familiares e sociedades anônimas. É verdade que a idéia do ciclo de vida da firma como solução ao problema teórico de conciliação entre rendimentos crescentes e concorrência pode ser questionada pela consideração da estrutura de propriedade e controle da moderna firma capitalista, gerenciada profissionalmente e, portanto, não sujeita à ossificação pelos mesmos fatores que afetam a firma familiar. Com efeito, o próprio Marshall propunha que (no momento em que escrevia) não era ainda possível avaliar em que medida a substituição da firma familiar pela sociedade anônima alterava a restrição vital que impede a firma de alcançar o monopólio com base nas economias internas. Mesmo sem uma posição conclusiva da parte do autor é possível recolher os elementos de sua discussão. ${ }^{15}$

Marshall alerta que a questão do desempenho das duas formas de organização não se refere ao aspecto meramente formal, mas às condições que efetivamente distinguem a sociedade anônima da firma familiar, ou seja, a separação de propriedade e controle. Isto porque praticamente qualquer ne-

14 Principles, livro IV, capítulo XI, $\$ 5$ e capítulo XII, $\$ 6$.

15 Principles, livro IV, capítulo XII, $\$ 8$ e 9 . Industry and Trade, livro II, capítulo VIII. 
gócio pode-se organizar por alguma modalidade de sociedade por ações mantendo as mesmas pessoas no controle - como no caso em que parte da família não é capaz ou não quer tomar parte na administração, ou no caso em que um grupo de capitalistas retém o controle e a liberdade de decisão em suas mãos da mesma forma que na sociedade familiar, quando distribuem ações preferenciais e debêntures ou mesmo ações ordinárias de forma pulverizada. ${ }^{16}$ Observe-se que, nestes casos, o ciclo de vida da firma se aplica da mesma forma que na firma familiar, dependentes que são das qualidades pessoais encontráveis entre os herdeiros na sucessão.

Devemos observar ainda que a proposição de um ambiente empresarial capitalista em permanente transformação implica que firmas que não se desempenham adequadamente na atividade inovadora estão fadadas ao declínio, sejam quais forem os arranjos de propriedade e controle. Esta pressão existente sobre eventuais candidatos a monopolistas ineficientes, exploradores das vantagens de seu tamanho, é qualificada ainda pela proposição marshalliana de que a concorrência potencial exercida por firmas que possam ser atraídas por preços elevados limita o poder de firmas que, na perspectiva teórica da concorrência tradicional, seriam pensadas como dotadas de elevado poder de monopólio. ${ }^{17}$

A desconfiança de Marshall em relação à firma organizada e profissionalmente gerida como sociedade anônima e seu enaltecimento da firma familiar se baseavam em argumentos que podem ser contemporaneamente enquadrados como problema de agência. Enquanto na firma familiar o controle e gerenciamento das operações estão centralizados nas mãos de um empresário que combina competência e auto-interesse para um desempenho produtivo, nas corporações:

"... o interesse privado do gerente assalariado [...] freqüentemente o leva em outra direção: o caminho de menor resistência, de maior conforto e menor risco para si ..."

(Industry and Trade, livro II, capítulo VIII, p. 324)

16 Industry and Trade, p. 317.

17 Industry and Trade, p. 396. 
“... aqueles que estão no controle possuem um interesse pecuniário no seu funcionamento econômico e eficiente muito menor de que teriam se fossem os proprietários do negócio."

(Industry and Trade, livro II, capítulo VIII, p. 317)

Assim, Marshall indica o ponto fraco das sociedades anônimas na gestão, que para ele tende a ser marcada pela rotina e ossificação. Nela os diretores podem manter seus cargos sem mostrar especial iniciativa. ${ }^{18}$ Inciativas de reconstrução de procedimentos e abandono de plantas ultrapassadas propostos por parte de diretores mais dinâmicos esbarram em dificuldades se as mudanças sugerem críticas a administrações passadas, e se as vantagens esperadas não podem ser provadas sem um grau de certeza absoluta. Conseqüentemente, a sociedade anônima acaba por adotar mudanças com maior dificuldade e menor agilidade do que a empresa conduzida por seu proprietário.

No entanto, as vantagens das corporações sobre empresas familiares em outras áreas ajudam a compensar as desvantagens apontadas na gestão. Assim, se já no caso geral o autor invoca as economias internas como prevalecentes na atividade industrial, ele aponta que nas sociedades anônimas o tamanho especialmente as favorece, como nas capacidades de atrair recursos financeiros e de contratar gerentes com conhecimento específico. Assim sendo, possuem vantagens para lastrear iniciativas, absorver conhecimento, empregar os melhores equipamentos, fazer compras em condições favoráveis. Entre as vantagens trazidas pelas economias internas está a facilidade de diversificação, que leva ao que o autor qualifica como excessivo alargamento do escopo das sociedades. Tais vantagens se exercem de forma problemática quando facilitam a entrada da firma na produção de novos itens, alimentando um processo de diversificação que pode se estender de forma a agravar os problemas de gestão, porque fatalmente envolve alguma transferência de administradores experimentados para os novos ramos onde não possuem conhecimento específico. Sublinhemos que aqui, mais uma vez, o problema é de gestão.

18 Industry and Trade, p. 317. 
A conclusão do balanço de vantagens e desvantagens das sociedades, no entender de Marshall, aponta saldo de vantagens do tamanho e acesso a capitais sobre desvantagens de gestão tíbia na forma de sobrevivência e mesmo preponderância como forma de organização, mas com performance inferior à que poderia apresentar se a firma fosse distintamente gerida. Note-se que isto não significa, para o autor, que o capitalismo teria entrado em decadência ou em uma fase de performance mais reduzida - Marshall tem claro o saldo de progresso trazido pelo ambiente de grandes corporaçóes da economia americana, descrito em seu Industry and Trade. ${ }^{19}$

A ABORDAGEM MARSHALLIANA DOS MERCADOS: COMERCIALIZAÇÃO DE PRODUTOS COMO FOCO

A visão marshalliana do funcionamento dos mercados pode ser descrita como marcada pela noção de que o encontro de compradores e vendedores não emerge espontaneamente. Pelo contrário, envolve esforço, recursos, organização, sendo adicionalmente uma atividade que pode ser diversamente organizada. Assim, são freqüentes as menções de Marshall à presença de agentes como corretores e intermediários nas relaçôes que se estabelecem entre firmas e mercados. O papel destes agentes pode ainda ser encampado pela firma produtora de bens, se esta crescer na direção da absorção de suas funções.

A ausência da identificação de agentes da comercialização pela microeconomia tradicional se explica pela adoção da concorrência perfeita como ideal. As hipóteses de produto homogêneo e perfeita informação prejudicam a compreensão de como os mercados funcionam, porque têm como corolário a firma estar dispensada de empreender esforços para vender seus produtos. O que as firmas precisam fazer neste mundo ideal é produzir empregando as técnicas mais econômicas, a que todas as firmas têm igual acesso. Agindo desta forma, e aceitando o preço impessoalmente determinado pelas forças de oferta e demanda, elas podem vender qualquer quantidade que desejam.

19 Vale registrar que as observações de Marshall sobre separação de propriedade e controle não só antecedem Berle e Means como se relacionam a um tema sempre renovado, a exemplo da recente vinda à tona de problemas corporativos na economia americana. 
E elas desejam vender a quantidade que iguala custos e receitas marginais (preço), porque as firmas são limitadas por rendimentos decrescentes que se manifestam como custos crescentes.

Devemos observar que Marshall não propôs o modelo de concorrência perfeita. O que se encontra em sua obra são observações dispersas envolvendo a noção de mercados perfeitos, mas isto se refere à condição extrema na qual todos têm informação completa a respeito das circunstâncias do mercado, presente em geral no caso dos bens que se qualificam como de uso geral, facilmente descritíveis, classificáveis e passíveis de representação por amostras, duráveis e de elevado valor em relação a peso e volume. Acrescentemos que a condição extrema se viabiliza por organização específica dos negócios, o fluxo de informações incluído - ou seja, depende do mercado apresentar determinados conteúdos institucionais. $\mathrm{O}$ resultado desta condição seria o mesmo preço ser praticado em todo o mercado. Exemplos de mercados em que isto ocorre são as bolsas de valores e os mercados onde se negociam metais preciosos. Conquanto esta descrição possa parecer semelhante à concorrência perfeita (com caracterização mais detalhada), devemos ter claro que Marshall não seguiu Walras em sua escolha da "concorrência no seu melhor ${ }^{20}$ como caracterização do ambiente institucional que informa a discussão de mercados, e mesmo na formulação de seu modelo de determinação de preços. Sua visão é melhor compreendida tendo por referência a sua afirmação de que a maioria dos mercados se encontra a meio caminho entre os da condição extrema e os mercados isolados onde a concorrência atua de forma muito amortecida. Ou seja, Marshall tem em mente condições competitivas, mas não a condição extrema que acabou por se reproduzir tanto no modelo de Walras como no que se incorporou à microeconomia como concorrência perfeita. Condições competitivas de Marshall são satisfatoriamente atendidas se há mobilidade de fatores e condições de informação razoáveis. Ou seja, concorrência potencial é importante, grande número de agentes não é obrigatório, e homogeneidade de produto não é condição. ${ }^{21}$

20 "...we shall suppose that the market is perfectly competitive, just as in pure mechanics we suppose, to start with, that machines are perfectly frictionless." (WALRAS, 1926, lição 5, $\$ 41$ ).

21 Devemos considerar ainda que, para Marshall assim como para os clássicos, a concorrência é um processo e não uma estrutura de mercado. Dentro desta visão, o autor contempla uma diversidade de situações a que as firmas podem fazer face, na sua luta por resultados econômicos. 
O tema da homogeneidade ou diferenciação de produtos aparece na obra de Marshall sob os conceitos de mercados "gerais" ou "particulares". Mesmo considerando que bens podem apresentar diferentes atributos com relação à demanda universal ou particular, Marshall não relacionou homogeneidade ou diferenciação a estruturas de mercado alternativas e diferentes modelos de formação de preços. Nos Principles, ${ }^{22}$ Marshall fala em mercados gerais e particulares relacionando-os a características das mercadorias. Ele aponta "produtos não acabados" e "simples e sem sofisticação" como trilhos de aço e tecidos de algodão como sendo tão simples e uniformes que podem ser vendidos por atacado em largas quantidades, podendo um produtor obter acesso à totalidade de um grande mercado. Por outro lado, "especialidades" (specialties) são mercadorias que "almejam criar novas necessidades ou satisfazer um antigo desejo de uma nova maneira." Neste caso, "as vendas de cada unidade de negócios são limitadas [...] ao mercado particular que ela lenta e dispendiosamente adquiriu." As vendas não podem aumentar tão rapidamente quanto a produção.

No Industry and Trade, Marshall oferece uma outra observação sobre mercados "gerais" e "particulares". No trecho abaixo, geral e particular não mais se referem a características intrínsecas às mercadorias, podendo aplicar-se a qualquer mercadoria:

"Todo produtor compra, e quase todo produtor vende, em alguma medida, em um mercado 'geral', no qual ele está em pé de igualdade com outros à sua volta. Mas quase todo produtor tem também mercados 'particulares'; ou seja, algumas pessoas ou grupos de pessoas com quem está em contato próximo: conbecimento mútuo e confiança levam a que ele seja procurado e a procurá-los, preferencialmente a estranhos.”

(Industry and Trade, Livro II, Capítulo I, $\$ 2$, p. 182)

Os usos distintos da oposição "geral x particular" podem ser ambos compreendidos como exposição de faces da diferenciação de produtos. Uma leitura institucionalmente orientada permite perceber que, enquanto na

22 Livro IV, capítulo XI, $\$ 6$.

Est. econ., São Paulo, 34(2): 369-392, abr-jun 2004 
primeira citação é sublinhado o aspecto de que diferentes bens requerem arranjos e esforços distintos em termos de comercialização, a segunda citação enfatiza a importância de conexões mercantis e a generalidade da questão da comercialização.

Os dois usos da oposição "geral x particular" chamam a atenção para a existência de uma questão adicional à mera produção de mercadorias, que é a de "fazer o mercado". ${ }^{23}$ Esta é uma questão geral, no sentido de que em sociedades em que a divisão do trabalho é complexa, é também complexo o encontro de compradores e vendedores, de forma que este não se dá de forma direta e simples, mas por meio de organização que envolve esforços e recursos. No âmbito da divisão do trabalho, os esforços e custos referentes à colocação de bens nos mercados podem ser objeto de firmas especializadas na intermediação, ou podem ser verticalizados pelos produtores, dando origem a uma diversidade de arranjos institucionais nos mercados segundo as mercadorias e épocas envolvidas.

UMA DIGRESSÃO: COMPREENDENDO INSTITUCIONALMENTE A ESCOLHA DO CONSUMIDOR COMO APLICAÇÃO DA IDÉIA DE "FAZER O MERCADO"

Os atacadistas desempenham o papel de alcançar varejistas dispersos, libertando os produtores deste esforço. Devem manter estoques de maneira a atender às encomendas de varejistas de maneira competitiva. Varejistas estão em contato com os consumidores, tendo informaçôes atualizadas sobre suas preferências e necessidades. Varejistas também devem manter estoques porque as mercadorias devem ser vistas pelo consumidor antes de serem compradas, já que estes são passivos enquanto compradores, no sentido de não fazer encomendas. ${ }^{24}$ Varejistas podem acumular reputação por meio de políticas de venda que aumentam seus custos tais como a aceitação de devolução de mercadorias. ${ }^{25}$ Como "compradores profissionais", os comerciantes conhecem as condições gerais dos mercados e formam expectativas sobre os movi-

23 Tradução para market making.

24 Contrasta, por exemplo, com a compra profissional de insumos por uma empresa.

25 Industry and Trade, p. 270.

Est. econ., São Paulo, 34(2): 369-392, abr-jun 2004 
mentos dos preços no futuro imediato. A discussão destes aspectos, presente na obra de Marshall, será feita por meio de proposições mais desenvolvidas por autores subsequientes, que podem ser consideradas marshallianas em sua concepção. $^{26}$

Se pensarmos no contato direto entre produtores e consumidores, este ocorria em mercados locais, que perderam sua importância com o desenvolvimento das economias de mercado. (JOAN ROBINSON, 1979). Hawtrey (1926) sugere que a intermediação pode ser vista como um estágio do processo de aprofundamento da divisão do trabalho. Em uma economia de mercado, a produção se faz em grandes quantidades por razões de economia, e os estoques são importantes para as vendas: os consumidores são passivos, a maior parte de suas compras não se faz por encomendas; são os intermediários que fazem as encomendas. Os bens são então avaliados e classificados para aos consumidores, com a exatidão e honestidade correspondente à manutenção das relações de clientela. Só então os bens são dispostos nas prateleiras à disposição da escolha dos consumidores.

Andrews (1964) aprofunda a observação acima, notando que os consumidores normalmente compram uma grande variedade de bens em uma "expedição" de compras, decidindo suas escolhas no local, o que dá importância aos estoques. Apenas bens duráveis e de grande valor unitário são objeto de uma viagem específica. Desta maneira, os custos do varejo não são atribuíveis a mercadorias individuais, e a formação de seus preços reflete mais as estratégias dos comerciantes para atrair consumidores do que os custos de mercadorias individualmente consideradas.

Assim, ao lado da usualmente reconhecida cadeia de produção, há uma cadeia de comercialização de importância vital para o funcionamento dos mercados. Atacadistas e varejistas são responsáveis por "fazer o mercado" para os produtores industriais. Consumidores são dispersos, da mesma forma que varejistas. Firmas industriais produzem em grande escala e atacadistas fracionam a grande massa de produtos, ao mesmo tempo que coletam bens com-

26 A seleção de autores e idéias apresentadas se faz com base no conteúdo marshalliano das citaçôes. Alguns destes autores se declararam explicitamente marshallianos, mas este não é o caso de todos os autores citados. 
plementares de um ramo comercial, produzidos por diferentes firmas. Os atacadistas vendem então a linha completa de bens a varejistas dispersos e pulverizados. Isto torna as vendas a consumidores mais econômicas.

As relações entre produtores, atacadistas e varejistas podem variar de acordo com setores, produtos e, principalmente, épocas históricas A caracterização acima deve ser adaptada, por exemplo, para considerar os produtos e a época do "capitalismo gerencial" que transformou as relações entre produção e distribuição da maneira descrita por Alfred Chandler (1977, 1990), com integração vertical de aspectos da comercialização e a emergência de varejistas em grande escala. No entanto, é importante ressaltar que nenhum desenvolvimento eliminou a distribuição e comercialização como questão a ser resolvida pela tarefa de "fazer o mercado", "time and thoughts of finding buyers", nas palavras de Hawtrey (1926). Mesmo na ausência de corretores e intermediários, esta atividade deve ser organizada ou verticalmente integrada pelos próprios produtores.

NÍVEL MÉDIO E SUPERIOR DE ORGANIZAÇÃO E CONHECIMENTO: DISTRITOS INDUSTRIAIS E NAÇÕES COMO AMBIENTES EMPRESARIAIS

A discussão de firmas e mercados não esgota a contribuição de Marshall à investigação dos negócios capitalistas. Há ainda os planos intermediários dos distritos industriais e o superior das economias nacionais que, reunindo capacidades e características compartilhadas pelos agentes e mercados participantes, representam um importante determinante do desempenho econômico de firmas, regiões e nações. Aqui, como nos outros pontos abordados anteriormente, Marshall combina proposições a diversos níveis de abstração, incluindo elementos históricos e institucionais.

Comecemos pelos distritos industriais. Além da já tratada possibilidade das economias internas, que operam em nível da firma individual, Marshall propôs também que o aumento da produção pode se acompanhar de redução de custos devido às economias externas. Estas correspondem às economias de aglomeração de vários negócios em uma região, de forma que as capaci- 
tações dos trabalhadores, os segredos da produção e serviços especializados são compartilhados pelos produtores locais que, adicionalmente, podem se especializar e adaptar seu equipamento a uma faixa estreita de operações, com subdivisão de uma extensa demanda entre vários tipos de produtos do mesmo gênero.

Embora o crescimento com base em economias externas represente uma alternativa ao crescimento com base nas economias internas, e que sempre se possa pensar no estreitamento do espaço da pequena empresa pelo desenvolvimento da grande, Marshall propõe que um espaço para crescimento de pequenas empresas é recriado pelo desenvolvimento das grandes - empresas de diferentes dimensões podem se complementar, ao invés de competir. Marshall fala no caso de pequenas unidades produtivas onde o conteúdo de trabalho é elevado, e que se beneficiam do fornecimento de materiais já processados de maneira padronizada pela produção em massa, concentrando fases de acabamento dos produtos.

No plano mais elevado das naçóes, encontramos no Industry and Trade uma análise de casos nacionais de desenvolvimento que indicam a importância de instituições e condicionantes históricos para o desempenho empresarial. ${ }^{27}$ Cada caso de preeminência industrial verificado na história é explicado por Marshall em termos de organização e vantagens próprias, relacionadas à época e a especificidades nacionais como a geografia e as instituições nacionais. A hegemonia industrial da Grã-Bretanha, precedida de primazia no comércio internacional, se formou de pequenas unidades de negócios, em ambiente de mudança lenta tanto na técnica como no caráter de bens e divisão de trabalho entre firmas nos distritos industriais. A hegemonia industrial passou a outros países que proporcionaram um ambiente mais fértil para as atividades produtivas de conteúdo científico elevado da chamada segunda revolução industrial. As instituições de educação e pesquisa, associadas a formas de coordenação dos capitais e novas formas de relacionamento de bancos e empresas, foram importantes no caso da ascensão da Alemanha como potência industrial. No caso americano, adicione-se às formas de aglutinação do capital a homogeneidade de estilos de vida em extensa popu-

27 Industry and Trade, Primeira parte. 
lação e mercado unificado pela ferrovia, de forma a favorecer a padronização e as economias de escala, de maneira autônoma em relação ao comércio internacional. Nos casos alemão e americano, a grande empresa e a aglutinação ou coordenação de capitais sob a forma de trustes ou cartéis desempenharam um papel central na estruturação da vida econômica, em consonância com a tendência mais geral de aumento na escala da produção e da comercialização, do desenvolvimento dos mercados de capitais e do processo de monopolização. Ainda no caso americano, as vantagens de economias internas introduzidas no processo de emergência das grandes corporações foram, para Marshall, temperadas com a legislação e o trabalho de agências antitruste, que estabeleceram um balizamento ao comportamento anticompetitivo, de forma a preservar minimamente o bem-estar econômico. $^{28}$

É importante observar que Marshall, tendo consciência de que a Inglaterra perdera a liderança industrial diante do desenvolvimento americano e alemão no início do século XX, sugere caminhos que não correspondem a copiar soluções destas experiências nacionais, mas desenvolvimentos a partir de características próprias. Independentemente da qualidade ou factibilidade das propostas marshallianas para recuperação de um posto preeminente na indústria internacional, é digno de nota a importância que ocupam a cultura e as instituições na visão de desenvolvimento de Marshall - este não pode ser obtido a partir de fórmulas que funcionariam da mesma maneira em qualquer ambiente.

\section{CONCLUSÃO}

A contribuição de Marshall à compreensão da atividade empresarial não se restringe ao modelo de equilíbrio parcial, ainda que tenha sido esta a peça teórica marshalliana exclusivamente incorporada pelo mainstream da teoria econômica. Há algumas maneiras de entender o conjunto formado pelo equilíbrio parcial e os elementos aqui discorridos. Se recorremos à distinção schumpeteriana de visão e análise, o equilíbrio parcial seria a análise mar-

28 Industry and Trade, Livro III, Capítulo VIII.

Est. econ., São Paulo, 34(2): 369-392, abr-jun 2004 
shalliana, e os elementos aqui explorados fariam parte de sua visão de funcionamento do capitalismo. Podemos ainda pensar que o equilíbrio parcial é um modelo estático para uma realidade que se sabe que é dinâmica; mas também devemos considerar que Marshall afirmou que a análise estática é apenas uma primeira aproximação aos problemas econômicos, e considerar que história e instituições receberam da parte do autor elevado apreço e foram objeto de elevado investimento em estudo e pesquisa.

Neste artigo é defendida a idéia de que, embora a discussão marshalliana de firmas e mercados tenha sido exposta pelo autor por meio de um estilo que torna trabalhosa sua absorção, houve uma importante perda de conteúdo explicativo no processo de constituição da microeconomia por meio da redução da teoria a um mero sistema de determinação de preços e alocação de recursos, com desprezo de elementos de discussão aqui sublinhados. Um argumento a favor da defesa desta idéia está na facilidade com que se percebe que a obra de Marshall antecipa aspectos de contribuições teóricas que se tornaram distintivas de outros autores ao longo do século XX, como Berle e Means, Penrose, Chandler, Nelson e Winter. Isto não é a afirmação de que a análise destes autores já estava presente na obra de Marshall de forma sistematizada; é a observação de que há em sua obra uma visão e uma agenda de pesquisa na qual os aspectos históricos e institucionais dos ambientes dos negócios capitalistas estão presentes de maneira esclarecedora.

Assim, a agenda de pesquisa marshalliana se manteve fértil e contemporânea. Isto se evidencia não só pela influência (consciente ou não) sobre a produção intelectual posterior, como principalmente pela existência de um conjunto de autores que se reconhecem como marshallianos, sendo G. B. Richardson (1972, 1998) e Brian Loasby (1991 e 1999) suas maiores expressões. $^{29}$

\section{REFERÊNCIAS BIBLIOGRÁFICAS}

ANDREWS, P. W. S. On competition in economic theory. London: Macmillan, 1964.

29 Ver também DOW \& EARL (1999) e FOSS \& LOASBY (1998), para artigos de autores neomarshallianos. 
CHANDLER, A. D. The visible hand: the managerial revolution in American business. Cambridge: Harvard U.P, 1977.

Scale and scope: the dynamics of industrial capitalism. Cambridge: Belknap P. of Harvard U.P., 1990.

Organizational capabilities and the theory of the firm. Journal of Economic Perspectives, v. 6, n. 3, p. 79-100.

COASE, R. H. Industrial organization: a proposal for research. In: . The firm, the market and the law. Chicago: The University of Chicago Press, 1988.

DOW, S. C.; EARL, P. E. (eds.) Economic organization and economic knowledge: essays in honor of Brian J. Loasby. 2 volumes. Aldershot: Edward Elgar, 1999.

FOSS, N. J.; LOASBY, B. J. (eds.) Economic organization, capabilities and co-ordination: essays in honor of G. B. Richardson. London: Routledge, 1998.

HAWTREY, R. G. The economic problem. Hyperion Press, 1980. Reprint from London: Longmans, 1926.

KERSTENETZKY, J. Uma discussão institucionalista de firma e mercado em Marshall. Revista de Economia Contemporânea v. 4, n. 1, p. 107122, jan./jul. 2000.

KNIGHT, F. H. Riesgo, incertidumbre y beneficio. Madrid: M. Aguilar, 1947. Edição original de 1921.

LANGLOIS, R; FOSS, N. J. Capabilities and governance: the rebirth of production in the theory of economic organization. Kyklos, v. 52, n. 2, p. 201-218, 1999.

LOASBY, Brian. Equilibrium and evolution. Manchester: Manchester U.P, 1991.

. Knowledge, institutions and evolution in economics. London: Routledge, 1999.

MARSHALL, Alfred. Industry and trade. London: Macmillan, 1920.

. Principles of economics. 8th. Ed. London: Macmillan, 1920.

MOSS, Scott. The history of the theory of the firm from Marshall to Robinson and Chamberlin: the source of positivism in economics. Economica, v. 51, n. 23, p. 307-18, Aug. 1984

ROBINSON, Joan. Markets. In: ford: Basil Blackwell, 1979. . Collected economic papers. Ox-

RICHARDSON, G. B. The organization of industry. Economic Journal, $82,1972$. 
. The economics of imperfect knowledge. Aldershot: Edward Elgar, 1998.

. Information and investment. Oxford: Oxford U.P., 1990.

SAMUELSON, P. A.; NORDHAUS, W. D. Economics. 14th ed. New York: McGraw-Hill, 1992.

SCHUMPETER, J. A. [1942] Capitalism, socialism and democracy. $5^{\text {th }} \mathrm{ed}$. George Allen \& Unwin, 1979.

WALRAS, L. Elements of pure economics. London: George Allen and Unwin, 1954. Tradução da edição original de 1926.

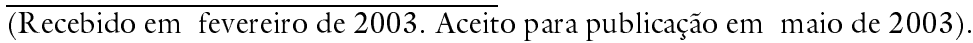

